\title{
Islam dan Multikulturalisme: Urgensi, Transformasi, dan Implementasi dalam Pendidikan Formal
}

\author{
Muhammad Turhan Yani ${ }^{\text {a) }}$, Totok Suyanto ${ }^{\text {b) }}$, Ahmad Ajib Ridlwan ${ }^{\text {c) }}$, Nur Fitroh Febrianto ${ }^{\text {d) }}$
}

a) Universitas Negeri Surabaya

b) Universitas Negeri Surabaya

c) Universitas Negeri Surabaya

d) Universitas Negeri Surabaya

\section{ABSTRAK}

Perkembangan masyarakat saat ini menunjukkan keterbukaan dalam menilai berbagai aspek kehidupan termasuk dalam pemahaman keagamaan. Hal ini menjadi tantangan karena selama ini sebagian masyarakat, khususnya sebagian umat Islam, masih memiliki sikap eksklusif. Menjawab tantangan tersebut, Islam sebagai ajaran universal berperan penting memberikan solusi melalui ajaranajarannya tentang esensi dasar multikulturalisme. Tulisan ini mengkaji secara teoritik kenyataan faktual multikulturalisme di Indonesia, bagaimana Islam memposisikan multikulturalisme, dan pandangan bagi lembaga pendidikan dalam mengembangkan perspektif multikulturalisme untuk tumbuhnya dan sikap inklusif di tengah masyarakat. Hasil kajian menunjukkan bahwa fakta multikulturalisme bangsa Indonesia merupakan suatu keniscayaan untuk dipelihara dan dikembangkan keberlangsungannya dengan mengedepankan sikap toleransi dan keadilan. Dalam perspektif Islam, multikulturalisme adalah fakta yang banyak ditemui pada al-Quran dan Hadits dan pada fakta historis kehidupan Nabi sendiri. Melalui saluran pendidikan, perspektif multikulturalisme dapat disemai untuk mengembangkan mengembangkan masyarakat yang menghargai nilai dan praktis kemajemukan itu sendiri.

\section{ABSTRACT}

The current development of society demonstrates openness in evaluating various aspects of life, including understanding towards religious matter. In another side, this fact turns into a challenge because some people, especially some Muslims, are still exclusive. Responding to the challenge, Islam as a set of universal principle should operate in providing solutions through its views upon the essence of multiculturalism. This paper examines theoretically the factual reality of multiculturalism in Indonesia, how Islam positions multiculturalism, and views for educational institutions in developing multiculturalism perspectives to grow inclusive attitudes in society. The results of the study show that the multiculturalism facts in Indonesia cannot be neglegted and must be maintained and developed by promoting tolerance and justice. In Islamic perspectives, multiculturalism is a fact that is often found in the al-Qur'an and Hadith as well as in the historical records of the Prophet's life. Through educational channels, the perspective of multiculturalism can be disseminated to develop a society that respects the value and practice of the multiculturalism itself.
KATA KUNCI

Islam; Multikulturalisme; Pendidikan.

\section{KEYWORDS}

Islam; Multiculturalism; Education.

\section{A. Pendahuluan}

Dinamika masyarakat dalam berbagai aspek kehidupan sosial, politik, ekonomi, budaya, dan agama pasca gerakan reformasi tahun 1998 di Indonesia telah mengantarkan bangsa ini pada pemahaman baru akan pentingnya nilai universal yang dapat mengikat semua perbedaan. Sesuai yang diungkapkan oleh Prasisko tahun 2016 bahwa gerakan reformasi tahun 1998 menghasilkan identitas dan 
Muhammad Turhan Yani, Totok Suyanto, Ahmad Ajib Ridlwan, Nur Fitroh Febrianto

nilai kultural yang beragam sebagai alat pemersatu bangsa. ${ }^{1}$ Dalam Islam, nilai-nilai universal memiliki kesamaan konsep Islam Rahmatan Lil 'Alamin sebagai misi mulia yang diemban oleh Nabi Muhammad SAW.

Namun pada praktiknya, umat Islam di Eropa justru tumbuh dengan stigma negatif dan menyeramkan. Pandangan tersebut muncul pada tahun 2011 ketika David Cameron mulai mengemukakan pandangannya mengenai radikalisme dan ekstremisme Islam sebagai ancaman keamanan NATO. ${ }^{2}$ Adanya topik ini tentunya berdampak pada pembatasan imigrasi bagi warga negara dari negara-negara Islam, seperti melakukan secara serius dan memaksa untuk tes kewarganegaraan di negara-negara NATO melalui Civic Integration Programs. Hal ini dimaksudkan agar warga negara yang tergabung dalam organisasi NATO mampu menempatkan kepentingan bangsa di atas kepentingan golongan sehingga terciptanya prinsip multikulturalisme.

Berbeda di Indonesia, nilai-nilai yang selama ini tumbuh pada sebagian masyarakat yang menekankan pada aspek keseragaman sudah sendirinya tidak dipertahankan lagi karena pola pikir seragam ternyata tidak dapat menjadi solusi efektif bagi bangsa ketika mengalami konflik horizontal. Sebagai contoh dalam bidang ekonomi, multikulturalisme justru akan menambah wawasan dan perspektif dalam menemukan solusi terkait permasalahan ekonomi. ${ }^{3}$ Sudah saatnya pola pikir keberagaman diberikan porsi yang seimbang sebagai cara pandang dalam berkehidupan, berbangsa, dan bernegara. Islam telah memberikan konsep multikulturalis sebagai suatu perspektif kehidupan yang memiliki dasar normatif dari teks-teks agama dan fakta historis.

Dalam kehidupan sosial, masyarakat modern dewasa ini yang terpenting untuk dikembangkan adalah sikap saling mengerti dan memahami. Sikap ini penting dimiliki oleh masyarakat agar terwujudnya kehidupan yang harmoni dan toleran. Untuk dapat memiliki sikap saling mengerti dan memahami tersebut, maka perlu dikembangkan pandangan multikulturalisme. Salah satu sarana yang tepat untuk mengembangkan pandangan multikulturalisme pada jangka panjang adalah melalui bidang pendidikan. Multikulturalisme pada pendidikan mampu memberikan kepercayaan diri, rasa nyaman, dan bebas menunjukkan tipikal perilaku budaya pada semua siswa. ${ }^{4}$ Dengan demikian siswa mampu memahami masing-masing teman yang berada di lingkungannya sehingga literasi mengenai keberagaman dapat langsung diterima.

Kebijakan pendidikan yang mengenalkan multikulturalisme secara modern pertama kali dikenalkan pada awal tahun 1990 ketika Pemerintah Inggris membentuk kurikulum yang menekankan

\footnotetext{
${ }^{1}$ Yangki Gigih Prasisko, "Gerakan Sosial Baru Indonesia: Reformasi 1998 dan Proses Demokratisasi Indonesia”, Jurnal Pemikiran sosiolog, Vol. 3 No. 2 (August 2016): 9-16.

${ }^{2}$ Michael A. Peters and Tina Besley, "Islam and the End of European Multiculturalism? From Multiculturalism to Civil Intergration", Policy Futures in Education, Vol.12, No. 1 (January 2014): 1-15.

${ }^{3}$ Eddy S. Ng and Isabel Metz, "Multiculturalism as a Strategy for National Competitiveness: The Case for Canada and Australia", Journal of Business Ethics, Vol. 128, No. 2 (February 2015): 253-66.

${ }^{4}$ Allyson Donoso, Katherin Ortega, and Patricio Andrés Pino Castillo, "Understanding the Meaning of Multicultural Collaboration in a Public-School EFL Class", International Journal of Multicultural Education, Vol. 22, No. 1 (2020): 115.
} 
pada kesetaraan manusia. ${ }^{5} \mathrm{Hal}$ ini dilakukan karena semakin banyaknya imigran yang masuk ke wilayah Inggris sehingga Pemerintah Inggris memiliki inisiatif untuk dapat menerapkan multikulturalisme pada bidang pendidikan sehingga memiliki dampak jangka panjang pada generasi muda untuk menciptakan keharmonisan diantara warga negara.

Lembaga pendidikan merupakan laboratorium kecil masyarakat untuk peserta didik melakukan sosialisasi terhadap berbagai nilai yang berkembang. Strategi pemberian "pengalaman" kepada siswa diharapkan mampu memproses transformasi nilai-nilai demokrasi masyarakat dengan dilakukannya secara terencana dan manusiawi. Penyelenggaraan pendidikan dimaksudkan agar memungkinkan seseorang dapat belajar, mendaptakan pengalaman, dan berbagi perspektif. Pendidik juga dapat memberikan kepada siswa kegiatan pembelajaran yang direkayasa secara sadar agar pengalaman itu dapat direncanakan, diimplementasikan, dan dievaluasi dari aspek kekinian, ketepatan, serta keefektifannya bagi pembentukan jiwa yang kreatif dan inovatif. Tanpa upaya sadar yang disertai komitmen tinggi, mustahil pendidik mampu memberikan pengalaman yang berharga bagi kehidupan siswa. Jika hal tersebut terjadi, maka siswa akan menjadi manusia yang tidak mandiri serta tidak mampu melakukan inovasi di dalam masyarakat.

Dipilihnya pendidikan sebagai sarana pengembangan pandangan multikulturalisme dikarenakan akhir ini terdapat fenomena sikap keberagamaan yang cenderung eksklusif di tengah masyarakat dan fenomena berkembangnya kelompok keagamaan yang cenderung radikal dan eksklusif. Namun, memberikan stigma negatif pada kelompok tertentu juga sangat menyesatkan dan menyebabkan adanya diskriminasi, hilangnya status warga negara hingga borosnya sumber daya untuk aktivitas kontra produktif. ${ }^{6}$ Untuk mengantisipasi berkembangnya fenomena eksklusivitas di tengah masyarakat, maka diperlukan perspektif multikulturalisme yang bersumber dari konsep Islam Rahmatan Lil 'Alamin.

Walaupun masih dirasakan baru, beberapa hasil empiris menunjukkan bahwa perspektif multikulturalisme dipandang penting, sebagaimana penelitian yang dilakukan oleh Ali Miftakhu Rosyad tahun 2020 tentang "The Integration of Is/amic Education and Multicultural Education in Indonesia" menunjukkan bahwa Islam dan pendidikan multikultural tidak dapat dipisahkan sebagai bagian penggerak moral siswa yang lebih beradab. ${ }^{7}$

Implementasi pendidikan kurikulum di sekolah dapat menggunakan model pembelajaran inovatif seperti pembelajaran kooperatif. Peningkatan keefektifan pembelajaran dengan perspektif multikulturalisme di madrasah, guru dapat dilakukan dengan menggunakan pendekatan multimedia. ${ }^{8}$

\footnotetext{
${ }^{5}$ Robert Jackson, "How Far Can Religious Education Contribute To Multicultural/Intercultural Education?", Scriptura, Vol. 89, (2013): 235-46.

${ }^{6}$ Susilo Wibisono, Winnifred R. Louis, and Jolanda Jetten, "A Multidimensional Analysis of Religious Extremism", Frontiers in Psychology, Vol. 10 (November 2019): 1-12.

${ }^{7}$ Ali Miftakhu Rosyad, "The Integration of Islamic Education and Multicultural Education in Indonesia. Al-Afkar, vol 3, No. 1 (January 2020):164-181.

${ }^{8}$ Warsono et. al., "Model Pengembangan Pendidikan Multikultur Bagi Siswa Madrasah Ibtidaiyah dengan Pendekatan Multimedia Sebagai Upaya Peningkatan Wawasan Kebangsaan. Jurnal Studi Islam, Sains, dan Teknologi, (2006).
} 
Muhammad Turhan Yani, Totok Suyanto, Ahmad Ajib Ridlwan, Nur Fitroh Febrianto

Dari beberapa temuan empiris tersebut, menunjukkan bahwa pendidikan menjadi salah satu sarana yang tepat untuk pengembangan multikulturalisme.

\section{B. Kenyataan Faktual Multikultural Indonesia}

Berbagai konflik horizontal maupun aksi kekerasan baik itu yang berbasis etnisitas, agama, maupun kedaerahan yang terjadi di Indonesia di penghujung abad XX mengantarkan kepada satu pemikiran bahwa hidup harmonis di negara yang bercorak multietnis, multireligi, dan multibudaya merupakan bayang-bayang semu. Fenomena tersebut seolah membenarkan tesis Huntington yang menyatakan bahwa konflik sosial ke depan tidak lagi didominasi oleh faktor-faktor politik, ekonomi dan ideologi namun juga dapat dipicu oleh faktor perbedaan budaya dan peradaban manusia. Realitas sosial menunjukkan bahwa bangsa Indonesia memiliki corak sebagai masyarakat multietnis dan multireligi. Hal ini juga diperkuat dengan penelitian yang dilakukan oleh Budirahayu pada tahun 2018 bahwa kalangan pemuda di Indonesia memiliki nilai pluralisme dan multikulturalisme yang cukup baik dan bahkan menjadi sebagian besar justru menjadi agen-agen perubahan pluralisme melalui media sosial. ${ }^{9}$

Bertolak dari pandangan di atas, model pengelolaan masyarakat yang seharusnya dikembangkan untuk masyarakat seperti Indonesia adalah paradigma atau perspektif multikultural dan bukan monokultural. Namun demikian selama lebih dari 30 tahun cara berpikir yang dikembangkan oleh negara adalah paradigma monokultur yang terlalu menekankan pada aspek persamaan, serta kurang memberikan porsi yang seimbang kepada keberbedaan. Beberapa negara lain multikulturalisme merupakan terapi bagi etnosentrisme, di Indonesia multikulturalisme bisa menjadi penyeimbang kesatuan.

Belajar pada multikulturalisme bidang ekonomi, cara berpikir yang terlalu menekankan pada aspek kesatuan atau kesamaan tidak dapat dijadikan sebagai solusi efektif ketika beberapa bagian dari wilayah negara ini dilanda aksi kekerasan massal dalam bentuk konflik horizontal. ${ }^{10}$ Oleh karena itu, sudah waktunya di era sekarang ini dikembangkan paradigma atau perspektif multikultural yang memiliki kelebihan dalam hal kesetaraan (equity) dan keadilan (justice) dibandingkan dengan cara berpikir monokultural. Masyarakat yang bercorak multikultural memiliki ciri-ciri utama sebagai berikut: keanekaragaman (diversity), persamaan (equality), interaksi melalui sharing, serta kesamaan akses pada berbagai sumber daya baik ekonomi, politik, maupun pendidikan. ${ }^{11}$ Ciri-ciri tersebut tidak dapat dikurangi salah satunya karena ketetapan itu merupakan hak mutlak setiap masyarakat untuk memperoleh keadilan yang bagian dari masyarakat multikultural. Hal tersebut sesuai dengan Parsudi

${ }^{9}$ Tuti Budirahayu, Marhaeni M. Wijayanti, and Katon Baskoro, "Understanding the Multiculturalism Values through Social Media among Indonesian Youths", Masyarakat, Kebudayaan Dan Politik, Vol. 31, No. 4 (December 2018): 42739.

${ }^{10}$ Anita Lie, "Keberagaman Budaya dan Otonomi Kurikulum" Dalam Pendidikan Nasional:Reformasi atau Resolusi", Analisis CSIS, Tahun XXIX,No. 3 (2000).

${ }^{11}$ Fattah Hanurawan and Peter Watereorth, "Multicultural Perspectives in Indonesian Social Studies Education Curriculum", The Journal of Education, Vol. 2, (December 1997): 265-275. 
Suparlan yang mengatakan bahwa acuan utama bagi terbentuknya masyarakat Indonesia yang multikultural adalah pengakuan dan pengagungan perbedaan dalam kesedarajatan baik secara individual maupun kebudayaan. ${ }^{12}$ Menurutnya, multikulturalisme bukan hanya sebuah wacana tetapi sebuah ideologi yang harus diperjuangkan karena dibutuhkan sebagai landasan bagi tegaknya demokrasi, HAM, dan kesejahteraan hidup masyarakat sehingga sangatlah tepat jika dapat diimplementasikan dalam semua aspek kehidupan.

\section{Multikulturalisme dalam Perspektif Islam}

Multikulturalisme dalam Islam sebenarnya telah ada pada zaman Nabi Muhammad SAW yang telah Allah sampaikan melalui Al-Quran sebagaimana pada Surah Al-Hujurat ayat 13 bahwa Allah telah menciptakan laki-laki dan perempuan, serta berbangsa dan bersuku-suku supaya saling mengenal. Perbedaan mendasar diantaranya adalah mengenai tingkat ketakwaan saja kepada Allah, bukan mengenai harta terlebih lagi warna kulit. Konsep multikulturalisme pada zaman Nabi Muhammad juga sebenarnya telah diimplementasikan pertama kali ketika beliau menolak konsep perbudakan kepada orang kelas bawah dan menuntut pembebasan kepada para pemimpin Quraisy. ${ }^{13}$ Hal tersebut merupakan pondasi dasar adanya nilai-nilai multikultural dalam Islam bahwa setiap manusia sejatinya sama di hadapan Allah.

Namun, saat ini adanya penolakan terjadi di kalangan umat Islam karena kurangnya pengetahuan dan informasi mengenai konsep multikulturalisme. Penolakan tersebut terkadang dikarenakan adanya kesalahpahaman mengenai konsep pruralisme dan multikulturalisme, padahal kedua konsep tersebut berbeda namun oleh sebagian pihak penggunaan kata tersebut digunakan bersamaan. ${ }^{14}$ Konsep pluralisme digunakan untuk bentuk toleransi terhadap kegiatan keagamaan, sedangkan multikulturalisme digunakan terhadap aktivitas sosial dan budaya.

Multikulturalisme merupakan sudut pandang yang bersumber dari konsep universal Islam yang disebut "Islam Rahmatan Lil 'Alamin" yaitu, ajaran Islam merupakan ajaran yang universal, mencakup segala aspek kehidupan manusia, rahmatnya tidak terbatas pada umat Islam saja. Akan tetapi pada semua manusia lintas agama, budaya, ras, dan etnis. Karena memang demikianlah realitas kehidupan manusia, yaitu masyarakat yang multikultural dan plural, yang terdiri dari berbagai suku, etnis, budaya dan agama yang berbeda. ${ }^{15}$

\footnotetext{
12 Parsudi Suparlan, "Kesetaraan Warga dan Hak Budaya Komuniti dalam Masyarakat Majemuk Indonesia", Antropologi Indonesia, Tahun XXV, No. 66 (Desember 2001).

${ }^{13}$ Dudung Abdurrahman, "Multiculturalism in Islamic Civilization During the Classic Period", Addin, Vol. 11, No. 1 (February 2017): 27-54.

${ }^{14} Z$ Zuli Qodir, "Islamic Thought, Nationalism, and Multiculturalism", Al-Albab, Vol. 3, No. 1 (June 2014): 25-38.

${ }^{15}$ Afandi Agus, Yani, and Muhammad Turhan, Islam Rahmatan Lil 'Alamin (Surabaya: Unesa University Presss, 2002), 76.
} 
Muhammad Turhan Yani, Totok Suyanto, Ahmad Ajib Ridlwan, Nur Fitroh Febrianto

Sebagai pijakan normatif tentang kajian ini, berikut beberapa dasar atau argumentasi diperlukannnya perspektif multikulturalisme dalam kehidupan sosial untuk mewujudkan sikap toleransi dan persaudaraan di tengah keragaman dan perbedaan, yang merupakan ciri masyarakat multikultural.

1. Ukhuwah Islamiyah, yaitu persaudaraan sesama umat Islam terdapat dalam Al-qur'an Surat AlHujurat: 10, dan hadits Nabi riwayat Imam Muslim sebagai berikut : Al-Muslimu akh al-muslimu, yang artinya bahwa sesama muslim adalah saudara.

2. Ukhuwah Basyariyah/Insaniyah, yaitu persaudaran sesama manusia lintas etnis/suku, bahasa, dan budaya) terdapat dalam Al-qur'an Surat Al-Hujurat: 13, Al-Maidah: 48, Al-Rum: 22).

3. Ukhuwah Diniyah, yaitu persaudaraan antarumat beragama terdapat dalam Al-qur'an Surat Yunus ayat 99 yaitu "Jikalau Tuhanmu menghendaki, tentulah semua manusia di muka bumi beriman. Maka apakah kamu akan memaksa manusia supaya menjadi orang-orang yang beriman?"

4. Ukhuwah Wathaniyah, yaitu persaudaraan antarwarga dan bangsa terdapat dalam Al-qur'an Surat Al-Hujurat: 13, yang artinya "Wahai manusia sesungguhnya Kami menciptakan kalian dari jenis laki-laki dan perempuan, dan kami jadikan kalian berbangsa-bangsa dan bersuku agar kalian saling mengenal". Pada dasarnya keragaman dan perbedaan, baik suku, budaya maupun agama adalah sunnatullah (sesuatu yang dikehendaki Allah)".

Sementara itu, ajaran agama sebenarnya mengajarkan umatnya tentang prinsip-prinsip multikulturalisme, yaitu ajaran untuk saling mengenal satu sama lain (ta'aruf) karena adanya perbedaan latar belakang budaya, etnik dan agama, bahasa, serta jenis kelamin. Akan tetapi secara historis-empirisfaktual, sesekali, untuk tidak mengatakan seringkali, dijumpai tindak kekerasan yang dilakukan oleh sebagian anggota masyarakat dengan dalih agama. Tentunya ini menjadi catatan tersendiri bagi para guru dan pendakwah untuk senantiasa meningkatkan literasi keilmuan agama. Penelitian dari Nurzakiyah juga telah menyebutkan bahwa kenyataannya masyarakat Indonesia saat ini sangat minim sekali atas literasi keagamaan yang tercermin dengan maraknya aktivitas tawuran, ketidakdisiplinan hidup, dan meningkatnya konflik horizontal. ${ }^{16}$ Dalam rangka peningkatan literasi keagamaan tentu dilakukan dengan berbagai cara, seperti dengan membaca, mencetak dalam bentuk visual, digital ataupun auditori. Cara tersebut dapat dengan mudah dipahamai oleh masyarakat Indonesia sehingga mampu memahami nilai-nilai substansi keagamaan. Hal ini sangat penting dilakukan agar masyarakat, khususnya generasi muda mampu hidup di tengah-tengah modernisasi.

Sedangkan menurut Alwi Shihab ajaran Islam itu inklusif, yakni rahmatnya tidak hanya untuk umat Islam saja, akan tetapi untuk semua umat manusia lintas agama, aliran, budaya, dan lain sebagainya, karena itu konsekuensi dari paradigma tersebut adalah perlu adanya sikap saling menghormati dan menghargai perbedaan yang ada, baik perbedaan agama, budaya, maupun yang lain-

\footnotetext{
${ }^{16}$ Cucu Nurzakiyah, "Literasi Agama Sebagai Alternatif Pendidikan Moral”, Jurnal Penelitian Agama, Vol. 19, No. 2 (August 2018): 20-29.
} 
lain sebagai suatu relitas sunnatullah. ${ }^{17}$ Sebuah hadits dari Kitab al-Hadits al-Dha'ifah wa al-Maudhu'ah Jilid 1 yang menjelaskan bahwa pentingnya belajar walaupun hingga ke Negeri China merupakan penghormatan kepada orang Tiongkok yang dikenal dengan agama Kong Hu Cu maupun Budha sehingga hal tersebut memberikan tanda bahwa agama Islam sangat menghargai peradaban bangsa lain yang lebih maju. ${ }^{18} \mathrm{Hal}$ ini menjadi petunjuk bagi seorang Islam untuk lebih dapat belajar banyak dan mengambil nilai-nilai positif dari peradaban negara non-Islam lainnya. Keberhasilan umat Islam tentu juga tidak terlepas dari umatnya yang senantiasa mengkaji dan belajar dari peradaban lainnya sehingga peradaban Islam mampu jaya pada abad pertengahan. Bagi peradaban Islam, salah satu tokoh yang paling penting dalam peradaban adalah Ibnu Rusyd yang mampu menyelaraskan antara filsafat dan agama. Padahal saat itu, filsafat masih menjadi budaya peradaban Bangsa Yunani. Namun, Al-Qur'an hakikatnya juga tidak seharusnya diambil pada nilai-nilai nominal namun juga tetap mempertimbangkan kembali ta'wil atau interpretasi rasional. Pandangan ini disampaikan oleh Ibnu Rusyd tentang keprihatinan tentang nasib perempuan yang tidak mendapatkan kesempatan dalam mengembangkan hidup dan nampak telah ditakdirkan sepenuhnya untuk melahirkan dan menjadi budak bagi suami. Hal ini menandakan Islam juga sangat mendukung adanya emansipasi wanita yang sering disuarakan oleh peradaban barat. ${ }^{19}$

Realitas Islam di Indonesia dikenal adanya dikotomi kelompok santri dan abangan. Salman Al Farizi menjelaskan bahwa dikotomi ini terjadi akibat pertandingan politik yang mengikuti lines of socialreligious. ${ }^{20}$ Kelompok Abangan menunjuk kepada masyarakat muslim syncretic-animist-budhist and Islam influencer dengan tradisi jawa yang masih dipertahankan, sedangkan kelompok santri dikenal dengan masyarakat muslim yang taat dandekat kepada budaya Arab dalam tradisi keagamaan. Dalam perspektif multikultural, adanya kelompok ini merupakan bagian dari multikultural yang terdapat di Islam. Hal ini telah disebutkan oleh Greetz bahwa masyarakat santri menjalankan ke-Islamannya melalui sinkretisme agama Islam dengan cara mengislamisasi ajaran-ajaran Hindu seperti tahlilan maupun upacara adat lainnya, sedangkan kelompok abangan menjalankan ke-Islamannya yang masih dipengaruhi perilaku animistik dan dinamistik. ${ }^{21}$ Walaupun secara hukum fiqih hal tersebut merupakan termasuk pada aspek furu' sehingga dapat diperdebatkan keabsahan aktivitas tersebut, namun secara tersirat Islam merupakan bagian dari multikulturalisme di Indonesia.

Multikulturalisme di Indonesia dalam keagamaan juga sudah seharusnya mampu dipahami secara luas termasuk mampu memahami gerakan antar organisasi kemasyarakatan, masalah furuiyah,

\footnotetext{
${ }^{17}$ Alwi Shihab, Islam Inklusif: Menuju Sikap Terbuka dalam Beragama (Bandung: Mizan, 1999), 98.

${ }^{18}$ Zuli Qodir, "Islamic Thought, Nationalism, and Multiculturalism"

${ }^{19}$ Zuli Qodir, "Islamic Thought, Nationalism, and Multiculturalism"

${ }^{20}$ Salman Al Farizi, "Apakah Dikotomi Santri-Abangan Cliffort Geertz Masih Relevan? Pertarungan Basis Sosial Partai Politik dalam Penyelenggaraan Pendidikan Kabupaten Jombang:, Jurnal Politik Muda, Vol. 6, No. 3 (AugustDecember 2017): 207-218.

${ }^{21}$ Cliffort Geertz, Agama Jawa: Abangan, Santri, Priyayi dalam Kebudayaan Jawa (Depok: Komunitas Bambu, 2014), 27.
} 
Muhammad Turhan Yani, Totok Suyanto, Ahmad Ajib Ridlwan, Nur Fitroh Febrianto

hingga prinsip organisasi lainnya. Hal ini penting sekali untuk dipahami oleh seluruh masyarakat karena akhir ini banyak sekali anggota ormas keagamaan yang saling menaruh curiga kepada ormas keagamaan yang lain padahal wawasan mengenai antar ormas tersebut sangat minim sekali. Bahkan dalam kasus fundamental, pembubaran salah satu organisasi masyarakat yang diduga tidak sepemahanan dengan nilai pancasila dan lebih memilih khilafah sebagai tujuan organisasi saja sangat minim sekali dialog antar umat Islam. Masyarakat langsung diberikan stigma bahwa tujuan khilafah tersebut tidak benar dan tidak sejalan dengan nilai pancasila. Padahal, masyarakat Indonesia dapat memperoleh pengetahuan yang lebih mendalam mengenai khilafah jika terdapat dialog ataupun debat di ruang terbuka antar sesama ormas maupun pemerintah. Seperti halnya kasus pada Etnis Danes yang memberikan pelajaran ke dunia bahwa pentingnya untuk berdialog hingga beradu argumentasi untuk memperoleh pemahaman yang multikultur dan terbuka. ${ }^{22}$

Sikap kritis dan realistis tentunya dapat dengan mudah diperoleh dengan adanya pandangan multikulturalisme melalui berbagai pendekatan di atas. Hal ini tentunya memberikan warna baru dalam transformasi seluruh sektor di masyarakat terlebih khusus pendidikan karena mampu membawa perilaku ilmiah yang sebelumnya hanya ada di kampus dan hanya diperoleh mahasiswa, dengan demikian perilaku ilmiah dapat dengan mudah dipahami oleh kalangan masyarakat yang memiliki pendidikan minim.

\section{Pendidikan sebagai Sarana Transformasi Multikulturalisme}

Pendidikan dipilih sebagai salah satu jalur untuk melakukan transformasi besar-besaran dalam upaya mendidik masyarakat memiliki wawasan terbuka (perspektif multikultural). ${ }^{23}$ Pandangan ini menitikberatkan pada fungsi dan peran pendidikan sebagai institusi yang dipercaya dalam melakukan transformasi nilai. Dalam kenyataannya, pendidikan memang menjadi sarana yang paling tepat dalam melakukan pengembangan perspektif multikulturalisme, hal ini ditandai bahwa sekolah dan perguruan tinggi yang melakukan proses pendidikan dan pembelajaran secara berkualitas dan menghargai perbedaan anak didik, telah menghasilkan lulusan yang baik dan bijaksana. Para pendidik dan karyawan yang terdapat di sekolah merupakan pengaruh utama untuk menentukan struktur sosial dan budaya sekolah sehingga keberagaman dapat diterima sehingga layanan pendidikan juga dapat diterima oleh seluruh siswa. ${ }^{24}$ Prinsip multikulturalisme menuntut adanya kesetaraan akses pendidikan untuk seluruh manusia. Hal ini sejalan dengan tujuan global yang digagas oleh UNESCO (United Nations Educational, Scientific, and Cultural Organization) bahwa pendidikan harus tetap memperhatikan kesetaraan gender

\footnotetext{
${ }^{22}$ Tina Gudrun Jensen, "The Cartoon Affair and the Question of Cultural Diversity in Denmark", E-Cadernos CES, Vol. 3 (2019): 64-73.

${ }^{23} Z$ ainuddin Maliki, "Pendidikan Multikultural di Madrasah”, Jurnal MDC Jatim, Vol. 1, No. 3, Tahun II (October 2004$)$.

${ }^{24}$ Irham, "Islamic Education at Multicultural Schools", Jurnal Pendidikan Islam, Vol. 3, No. 2 (December 2018): 141-54.
} 
dengan mendorong lebih banyak anak perempuan untuk memasuki bidang sains, teknologi, teknik dan matematika. ${ }^{25}$

Bank Dunia menyatakan ada tiga hal yang harus diwujudkan melalui pendidikan, yaitu: pembangunan modal manusia sehingga lahir manusia-manusia produktif, (2) manusia yang sehat dengan nutrisi yang baik, dan (3) pembangunan modal sosial. Melalui perwujudan tigal hal tersebut pendidikan bisa membantu mewujudkan rasa keadilan, kohesi sosial di tengah kehidupan manusia yang beraneka ragam latar belakang sosial budaya. maupun ekonomi politik nasional. Konstruksi politik sosial yang dihasilkan dengan adanya multikultural akan semakin konstruktif dan berkembang karena memungkinkan adanya perspektif lain yang dihasilkan dengan adanya perbedaan budaya yang dianut. Multikulturalisme sendiri bertujuan sebagai alat integrasi sosial dan persatuan masyarakat sipil sehingga dalam aspek pembuatan kebijakan mampu mengakui adanya pentingnya budaya, kesehatan, dan kesejahteraan individu. ${ }^{26}$ Dengan cara inilah sejumlah kelompok mampu menjalin relasi dengan mayoritas lainnya dengan tidak meninggalkan nilai, budaya, ataupun visi hidup tertentu.

Dalam konteks inilah perspektif multikuturalisme menjadi pilihan yang strategis karena akan disemaikan nilai-nilai keberagaman, serta pengakuan dan penghargaan keunikan akan budaya berbagai kelompok sosial. Melalui perspektif multikultural setiap individu dengan perbedaan latar belakang sosial, etnisitas, dan budayanya akan memiliki kedudukan yang sama dalam sistem sosial. Penyemaian nilai-nilai multikultural melalui jalur pendidikan formal merupakan pilihan strategis karena salah satu pilar pendidikan dibangun atas dasar learning to live together. Learning to live together merupakan pengajaran yang bertujuan untuk saling melengkapi, mengarah pada pengembangan empati, kepekaan budaya, keterampilan komunikasi, kerja tim, dan kepemimpinan. ${ }^{27}$

Pada gilirannya penyampaian nilai-nilai tersebut akan berkorelasi positif dengan terciptanya kohesi sosial dan secara langsung akan memperkuat modal sosial. Barangkali inilah sumbangan pendidikan untuk menjawab kebutuhan masyarakat akan kedamaian, penyelesaian konflik dan kekerasan.

Pendidikan dalam Islam dipandang sebagai proses pembelajaran yang holistik yang meliputi tarbiyah, ta'lim, dan ta'dib dengan beberapa pendekatan pikiran, hati, dan jiwa sehingga agama bukanlah sebagai seperangkat ritual keagaamaan saja namun lebih kepada sistem yang mencakup dan mengintegrasikan aspek intelektual, moral, sosial, emosional, dan manusia. ${ }^{28}$ Konsep pendidikan ini yang sudah seharusnya diterapkan dan disesuaikan dengan keberagaman yang terdapat di Indonesia.

\footnotetext{
${ }^{25}$ Ellen Boeren, "Understanding Sustainable Development Goal (SDG) 4 on "Quality Education" from Micro, Meso and Macro Perspectives", International Review of Education, Vol. 65, No. 2 (March 2019): 277-294.

${ }^{26}$ Laurence J. Kirmayer, “The Politics of Diversity: Pruralism, Multiculturalism, and Mental Health”, Trancultural Psychiatry, Vol. 56, No. 6 (November 2019): 1119-1138.

${ }^{27}$ UNESCO, Learning to Live Together: Education Polices and Realitis in the Asia-Pacific (Paris: Place De Fontenoy, 2014), 6.

${ }^{28}$ Naima Lafrarchi, "Assessing Islamic Religious Education Curriculum in Flemish Public Secondary Schools", Religions, Vol. 11, No. 3 (March 2020): 1-29.
} 
Muhammad Turhan Yani, Totok Suyanto, Ahmad Ajib Ridlwan, Nur Fitroh Febrianto

Beberapa cara untuk merelasikan antara Islam dengan pendidikan multikulturalisme yaitu dengan mengambil dan mengkomparasikan realitas orientasi dari berbagai paham, membuat strategi yang berbeda dengan mengkomparasikan pendidikan Islam yang ada di berbagai negara muslim, dan menyamakan persepsi dengan menyesuaikan sosial budaya yang berkembang di masyarakat atau dapat disebut pendidikan multikultural-religius.

Peran pendidikan multikultural-religius sebagai salah satu sisi kemanusiaan dan nilai keagamaan melalui dekadensi moral-spiritual akibat adanya dampak negatif globalisasi. ${ }^{29}$ Artinya kemanusiaan dan nilai keagamaan mampu memberikan manfaat pada pembangunan multikultural pada aspek religius sehingga masyarakat akan semakin memiliki nilai toleransi yang semakin tinggi. Jika pemahaman terhadap nilai keagamaan dipegang secara tekstual, maka sikap eksklusif dalam beragamapun akan sulit untuk dihindari sehingga menyebabkan fanatisme buta dan intoleran. ${ }^{30}$ Pada jangka panjang, tentunya hal tersebut merupakan tantangan sekaligus kendala bagi pembangunan nasional di masa mendatang karena harus disibukkan dengan perbedaan visi pembangunan berdasarkan etnis maupun suku.

Perpecahan etnis memang sering digunakan sebagai alasan untuk menjelaskan perselisihan diantara masyarakat sipil. Hal ini sesuai dengan penelitian dari Danie Nettle, dkk yang menyebutkan bahwa ketidakstabilan sosial memang terjadi akibat karena adanya pengaruh keanekaragaman sehingga semakin banyak yang beragam maka kemungkinan terjadinya konflik sosial akan semakin besar. ${ }^{31}$ Nettle, dkk. juga menjelaskan dalam kesimpulan penelitiannya bahwa kinerja ekonomi yang buruk dan ketimpangan ekonomi sangat berkaitan dengan ketidakstabilan sosial. Namun, Nettle, dkk. juga memberikan pandangan yang lebih universal untuk bisa jadi pengaruh tersebut diakibatkan kualitas data linguistik saja.

Efek multidimensi yang dihasilkan adanya pendidikan yang multikultural bagi pembangunan nasional memang sangat besar, salah satunya adalah terciptanya tenaga kerja yang memiliki inovasi beragam, mampu memanfaatkan keberagaman ekonomi global, serta mampu memanfaatkan organisasi ke dalam posisi yang lebih beruntung sehingga dapat meningkatkan pangsa pasar. ${ }^{32}$ Namun, jika pendidikan tidak mampu memberikan dampak bagi pembangunan nasional maka terjadinya konflik horizontal seperti adanya diskriminasi bagi etnis maupun golongan tertentu. Dengan demikian, memang sudah semestinya multikultural merupakan kunci dari segala pembangunan bangsa yang menekankan pada aspek pemeraatan, keadilan, dan kebermanfaatan bagi seluruh masyarakat secara luas. Sudah

\footnotetext{
${ }^{29}$ Zainal Arifim, "Pendidikan Multikultural-Religius Untuk Mewujudkan Karakter Peserta Didik Yang Humanis-Religius, Jurnal Pendidikan Serambi Ilmu, Vol. 1, No. 1 (June 2009): 89-103.

${ }^{30}$ Achmad Rois, "Pendidikan Islam Multikultural: Telaah Pemikiran Muhammad Amin Abdullah", Epistemé: Jurnal Pengembangan Ilmu Keislaman, Vol. 8, No. 2 (December 2013): 302-22.

${ }^{31}$ Nettle Daniel et. al. “Cultural Diversity, Economic Development and Societal Instability”, PloS One, No. 9 (September 2007): 1-5.

${ }^{32}$ Swinton W. Hudson, "Diversity in the Workforce", Journal of Education and Human Development, Vol. 3, No. 4 (December 2014): 73-82.
} 
semestinya memang pendidikan didesain untuk memberikan pemahaman komprehensif kepada siswa mengenai multikultural sebagai pondasi substansial pembangunan masa depan.

\section{E. Urgensi Pendidikan Multikultural dan Implementasinya}

Adanya pendidikan multikultural sudah seharusnya didesain untuk mengantisipasi adanya konflik horizontal. Melalui suatu gerakan reformasi proses yang tujuan utamanya adalah untuk merubah mekanisme pendidikan yang lebih universal. Pendidikan multikultural terdiri atas berbagai kepercayaan dan penjelasan yang mengakui dan menilai akan pentingnya keberagaman budaya dan etnisitas yang di dalamnya meliputi gaya hidup, pengalaman-pengalaman sosial, identitas personal, serta kesamaan kesempatan untuk memperoleh pendidikan baik dalam tingkatan individu, kelompok sosial, maupun bangsa. ${ }^{33}$

Pendidikan multikultur dapat dikonseptualisasi dan diformulasikan sebagai sebuah lapangan yang terdiri atas lima dimensi yang dapat digunakan dalam pelatihan guru. Dimensi-dimensi tersebut didasarkan atas penelitian, observasi, dan kajiannya selama bertahun-tahun sejak tahun 1960. Dimensi tersebut adalah (1) integrasi bahan (content integration), (2) proses mengkonstruksikan pengetahuan (the knowledge construction process), (3) mengurangi prasangka (prejudice reduction), (4) kesamaan pedagogis (pedagogy equity), dan (5) pemberdayaan budaya sekolah dan struktur masyarakat (empowering school culture and social structure).

Integrasi bahan berkaitan dengan keluasan di mana guru menggunakan berbagai contoh, data, dan informasi dari berbagai budaya dan kelompok (sosial) untuk mengilustrasikan berbagai konsep, prinsip, generalisasi, dan teori kunci dalam disiplin atau bidang kajian mereka. Proses konstruksi pengetahuan mendeskripsikan berbagai prosedur yang dilakukan oleh ilmuwan, baik dalam bidang ilmu sosial, keperilakuan, maupun kealaman dalam menciptakan pengetahuan, dan cara-cara dimana asumsi-asumsi budaya implisit, kerangka berpikir, perspektif serta bias-bias dalam suatu disiplin (keilmuan) yang mempengaruhi cara-cara pengetahuan tersebut dikonstruksikan. Apabila proses konstruksi pengetahuan itu dilaksanakan di dalam kelas, guru-guru harus membantu siswa untuk memahami bagaimana pengetahuan diciptakan dan bagaimana perbedaan ras dan etnik mempengaruhi, baik pengetahuan maupun posisi sosial dari setiap individu dan kelompok.

Kesamaan pendidikan terjadi ketika guru menggunakan berbagai teknik, dan metode yang memfasilitasi pencapaian akademik siswa dari berbagai ras, etnik, dan kelompok-kelompok kelas sosial. Konsep pemberdayaan budaya sekolah dan struktur sosial digunakan untuk mendeskripsikan proses merekonstruksi budaya dan organisasi sekolah sehingga siswa dari berbagai kelompok ras, etnik, dan kelompok kelas sosial akan mengalami kesamaan pendidikan dan pemberdayaan budaya. Ciri khas dari

\footnotetext{
33 James A. Banks, Multicultural Education for Young Children: Racial and Ethnic Attitudes and Their Modification (New York: Macmillan, 1993), 45.
} 
Muhammad Turhan Yani, Totok Suyanto, Ahmad Ajib Ridlwan, Nur Fitroh Febrianto

pendidikan multikultural adalah tetap mempertahankan dan mempelajari kebudayaan masing-masing orang sehingga kebudayaan yang ada tidak memudar dan terus dipelajari oleh generasi selanjutnya. ${ }^{34}$

Pendidikan multikultural di Indonesia merupakan bidang kajian yang relatif baru sehingga secara eksplisit belum termuat dalam kurikulum. Hal ini juga dibenarkan oleh Chang Yau Hoo ketika meneliti pendidikan kewarganegaraan multikultural yang menjelaskan bahwa pemerintah Indonesia belum memiliki visi yang jelas mengenai pendidikan multikultural meskipun telah memiliki undang-undang pendidikan tahun 2003 dan panduannya tahun 2007 untuk penerapan model pendidikan multikultural untuk tingkat menengah. ${ }^{35} \mathrm{Hal}$ ini karena pemerintah masih beranggapan bahwa multikulturalisme yang bisa dipelajari secara alami di sekolah. Oleh sebab itu, strategi yang dapat dikembangkan oleh guru dalam mengimplementasikan pendidikan multikultur di sekolah adalah strategi inklusif dan mengajarkan dalam bidang bentuk kegiatan ekstrakurikuler. Dalam strategi inklusif guru mengajarkan materi pendidikan multikultural dengan cara menyisipkan (to infuse) pendidikan multikultural dalam mata pelajaran yang sudah ada, melalui pengembangan tema esensial dalam mata pelajaran. Dengan mempertimbangkan tingkat kematangan berpikir siswa strategi inklusif lebih cocok digunakan untuk siswa pada jenjang pendidikan dasar. Bentuk alternatif yang dapat digunakan guru untuk mengimplementasikan pendidikan multikultural di sekolah adalah melalui kegiatan ekstrakurikuler yang pelaksanaannya di luar jam sekolah. Melalui bentuk ini masalah keterbatasan waktu belajar dapat diatasi dan justru kreativitas guru dapat dikembangkan secara optimal.

Parameter keberhasilan pendidikan multikultur tidak hanya menekankan pada aspek kognitif belaka, namun juga pada tataran afektif dalam bentuk sikap dan perilaku siswa, maupun pada ranah psikomotorik dalam bentuk keterampilan sosial siswa untuk hidup dalam masyarakat yang multikultural. Secara implementatif adalah sebagai berikut: ${ }^{36}$

1. Mampu menguasai kompetensi dasar yang dikembangkan dalam pendidikan multikur

2. Mampu mengajak komunitas sosial yang ada di berbagai daerah untuk menyampaikan pesan mengenai kesejahteraan sosial, pengembangan pribadi, serta pekerjaan di masa mendatang.

Sedangkan, kompetensi dasar yang wajib dikembangkan dalam pendidikan multikultural adalah sebagai berikut: ${ }^{37}$

1. Cara menghargai perbedaan etnis, agama, bahasa, gender, dan budaya dalam struktrur masyarakat.

2. Menjadi warga negara yang bisa bekerja sama antara multi-etnis, multikultural, dan multi-agama dalam konteks pembagunan.

\footnotetext{
${ }^{34} J u n h a o$ Zhang, "Educational Diversity and Ethnic Cultural Heritage in the Process of Globalization", International Journal of Anthropology and Ethnology, Vol. 3, No. 7 (May 2019): 1-10.

${ }^{35}$ Chang Yau Hoon, "Multicultural Citizenship Education in Indonesia: The Case of a Chinese Christian School Multicultural Citizenship Education in Indonesia : The Case of A", Journal of Southeast Asian Studies, Vol. 44, No. 3 (October 2013): 490=510.

${ }^{36} \mathrm{Mel}$ Ainscow, "Diversity and Equity: A Global Education Challenge", New Zealand Journal of Educational Studies, Vol. 51, No. 2 (September 2016): 143-155.

${ }^{37}$ Slamet, Masrukhi, Haryono, and Wasino, "The Implementation of Multicultural Values in The Educational Insitution", The Journal of Educational Development, Vol. 5, No. 1 (February 2017): 118-127.
} 
3. Saling menghormati hak warga negara.

Strategi mengimplementasikan pendidikan multikultural di institusi pendidikan formal melalui beberapa cara, diantaranya:

1. Mengajarkan bukan hanya sebatas kata namun peserta didik didorong untuk mencari informasi atau bercerita tentang pengalaman pribadi.

2. Merasakan secara langsung bagaimana budaya masing-masing daerah.

3. Peserta didik diminta untuk mengaitkan korelasinya dengan pengetahuan awal yang dimiliki.

Berbagai cara sebenarnya dapat dilakukan pengajar untuk memasukkan nilai multikultural salah satunya juga dengan cara strategi inklusif yaitu matakuliah agama yang dibahas melalui perspektif multikultural dan dikembangkan dalam berbagai tema. Hal ini karena pembelajaran agama tidak hanya berfokus pada pengetahuan saja sebagai objek studi, namun lebih luas lagi pada aspek moralitas sehingga identitas Islam tidak hilang dengan adanya era digital dan tuntutan multikultural. ${ }^{38}$ Pengembangan perkuliahan PAI di perguruan tinggi dengan multikulturalisme sebagai upaya untuk mencapai tujuan pendidikan yang sesuai dengan kepribadian bangsa Indonesia, yakni: (a) menerima dan melaksanakan Pancasila dan Undang-Undang Dasar Negara Republik Indonesia Tahun 1945, (b) menerima dan melaksanakan agama Islam sesuai ketentuan dan menghormati agama serta kepercayaan orang lain, (c) mencintai sesama manusia, bangsa, dan lingkungan sekitarnya, (d) dapat menghargai kebudayaan nasional yang beraneka ragam, mulai dari suku, budaya, agama, dan sebagainya.

Pendidikan multikultural menjadi penting karena konflik dan kekerasan antar SARA akan terus tercipta hingga problema multikultural tidak akan terselesaikan dan kehidupan yang damai tidak akan terwujudkan. ${ }^{39} \mathrm{Hal}$ ini didukung oleh penelitian yang dilakukan oleh Samson tahun 2018 bahwa secara psikologis sosial adanya rasa isyarat eksperimental dari etnis mayoritas yang mengharapkan etnis minoritas menjadi bagiannya sehingga menyebabkan meningkatnya bias rasial dan menurunkan kehangatan terhadap minoritas. ${ }^{40}$ Danes atau Etnis Denmark telah memberikan pelajaran bagi berkembangnya multikultural di negara tersebut. Adanya polarisasi antara Danes dan orang Muslim imigran membuat konflik berkepanjangan dan benturan peradaban karena minimnya rasa ingin tahu. Namun, hal tersebut terselesaikan dengan adanya dialog terbuka, debat hingga konferensi antara Danes dengan orang-orang Muslim mengenai keragaman dan persatuan hingga merubah sikap stereotip orang etnis Denmark. ${ }^{41}$

\footnotetext{
${ }^{38}$ Moch Tolchah and Muhammad Arfan Mu'ammar, "Islamic Education In The Globalization Era; Challenges , Opportunities, And Contribution Of Islamic Education In Indonesia", Humanities \& Social Sciences Reviews, Vol. 7, No. 4 (October 2019): 1031-1037.

39 Zainuddin Maliki, "Pendidikan Multikultural di Madrasah"

${ }^{40}$ Frank L. Samson, "An Association between Multiculturalism and Psychological Distress", PLoS ONE, Vol. 13, No. 12 (December 2018): 1-15.

${ }^{41}$ Tina Gudrun Jensen, "The Cartoon Affair and the Question of Cultural Diversity in Denmark"
} 
Muhammad Turhan Yani, Totok Suyanto, Ahmad Ajib Ridlwan, Nur Fitroh Febrianto

Urgensi pendidikan multkultural memang mendorong siswa untuk lebih terbuka dengan adanya berbagai budaya melalui komunikasi yang lebih intensif, beradu argumen, hingga pendekatan personal. Dengan demikian, akan terciptanya keharmonisan diantara siswa dengan berbagai latar belakang etnis dan budaya. Kesalahpahaman pendidik saat ini memang terlalu mengedepankan toleransi tanpa adanya pembahasan mengapa siswa harus melakukan demikian padahal jika siswa didorong untuk lebih kritis dan peduli maka budaya bangsa akan semakin konstruktif ataupun berkembang karena mampu menyeleksi budaya yang sesuai dengan hakikat manusia dan perkembangan zaman. Tuntutan ini dibentuk agar siswa juga semakin realistis dalam menerapkan nilai-nilai multikultural namun sesuai dengan aturan yang berada di agama Islam. Kentungan adanya hal tersebut adalah sikap toleransi yang masih sesuai dengan akhlak karimah.

\section{F. Kesimpulan}

Pendidikan sebagai salah satu cara untuk melakukan transformasi dalam upaya mendidik masyarakat memiliki wawasan terbuka menitikberatkan pada pengembangan perspektif multikulturalisme. Hal tersebut yang ditandai dengan sekolah dan perguruan tinggi yang melakukan proses pendidikan dan pembelajaran secara berkualitas dan menghargai perbedaan anak didik, telah menghasilkan lulusan yang baik dan bijaksana. Adanya pendidikan multikultural sudah seharusnya didesain untuk mengantisipasi adanya konflik horizontal melalui suatu gerakan reformasi untuk merubah mekanisme pendidikan yang lebih universal. Beberapa parameter keberhasilan adanya pendidikan multikultural adalah penguasaan kompetensi dasar dan mampu memberikan dampak langsung ke masyarakat. Implementasi pendidikan multikultural dilakukan dengan berbagai cara, salah satunya melalui strategi inklusif.

\section{G. Referensi}

Abdurrahman, Dudung. "Multiculturalism in Islamic Civilization During the Classic Period", Addin, Vol. 11, No. 1 (February 2017): 27-54.

Agus, Afandi et. al. Islam Rahmatan Lil ‘Alamin. Surabaya: Unesa University Presss, 2002.

Ainscow, Mel. "Diversity and Equity: A Global Education Challenge", New Zealand Journal of Educational Studies, Vol. 51, No. 2 (September 2016): 143-155.

Arifim, Zainal. "Pendidikan Multikultural-Religius Untuk Mewujudkan Karakter Peserta Didik Yang Humanis-Religius, Jurnal Pendidikan Serambi Ilmu, Vol. 1, No. 1 (June 2009): 89-103.

Banks, James A. Multicultural Education for Young Children: Racial and Ethnic Attitudes and Their Modification. New York: Macmillan, 1993.

Budirahayu, Tuti et. al.. "Understanding the Multiculturalism Values through Social Media among Indonesian Youths", Masyarakat, Kebudayaan Dan Politik, Vol. 31, No. 4 (December 2018): 42739. 
Boeren, Ellen. "Understanding Sustainable Development Goal (SDG) 4 on "Quality Education" from Micro, Meso and Macro Perspectives", International Review of Education, Vol. 65, No. 2 (March 2019): 277-294.

Daniel, Nettle et. al. "Cultural Diversity, Economic Development and Societal Instability", PloS One, No. 9 (September 2007): 1-5.

Donoso, Allyson et. al. "Understanding the Meaning of Multicultural Collaboration in a Public-School EFL Class", International Journal of Multicultural Education, Vol. 22, No. 1 (2020): 1-15.

Farizi, Salman Al. "Apakah Dikotomi Santri-Abangan Cliffort Geertz Masih Relevan? Pertarungan Basis Sosial Partai Politik dalam Penyelenggaraan Pendidikan Kabupaten Jombang", Jurnal Politik Muda, Vol. 6, No. 3 (August-December 2017): 207-218.

Geertz, Cliffort. Agama Jawa: Abangan, Santri, Priyayi dalam Kebudayaan Jawa. Depok: Komunitas Bambu, 2014

Hanurawan, Fattah and Watereorth, Peter. "Multicultural Perspectives in Indonesian Social Studies Education Curriculum", The Journal of Education, Vol. 2, (December 1997): 265-275.

Hoon, Chang Yau. "Multicultural Citizenship Education in Indonesia: The Case of a Chinese Christian School Multicultural Citizenship Education in Indonesia : The Case of A", Journal of Southeast Asian Studies, Vol. 44, No. 3 (October 2013): 490=510.

Hudson, Swinton W. "Diversity in the Workforce", Journal of Education and Human Development, Vol. 3, No. 4 (December 2014): 73-82.

Irham. "Islamic Education at Multicultural Schools", Jurnal Pendidikan Islam, Vol. 3, No. 2 (December 2018): 141-154.

Jackson, Robert. "How Far Can Religious Education Contribute To Multicultural/Intercultural Education?", Scriptura, Vol. 89, (2013): 235-46.

Jensen, Tina Gudrun. "The Cartoon Affair and the Question of Cultural Diversity in Denmark", E-Cadernos CES, Vol. 3 (2019): 64-73.

Kirmayer, Laurence J. "The Politics of Diversity: Pruralism, Multiculturalism, and Mental Health", Trancultural Psychiatry, Vol. 56, No. 6 (November 2019): 1119-1138.

Kivisto, Peter. "(Mis)Reading Muslims and Multiculturalism", Social Inclusion, Vol. 1, No. 2 (November 2013): 126-35.

Lafrarchi, Naima. "Assessing Islamic Religious Education Curriculum in Flemish Public Secondary Schools", Religions, Vol. 11, No. 3 (March 2020): 1-29.

Lie, Anita et. al. "Keberagaman Budaya dan Otonomi Kurikulum" Dalam Pendidikan Nasional:Reformasi atau Resolusi", Analisis CSIS, Tahun XXIX, No. 3 (2000).

Maliki, Zainuddin. "Pendidikan Multikultural di Madrasah", Jurnal MDC Jatim, Vol. 1, No. 3, Tahun II (October 2004).

$\mathrm{Ng}$, Eddy S. and Metz, Isabel. "Multiculturalism as a Strategy for National Competitiveness: The Case for Canada and Australia", Journal of Business Ethics, Vol. 128, No. 2 (February 2015): 253-66. 
Nurzakiyah, Cucu. "Literasi Agama Sebagai Alternatif Pendidikan Moral", Jurnal Penelitian Agama, Vol. 19, No. 2 (August 2018): 20-29.

Peters, Michael A. and Besley, Tina. "Islam and the End of European Multiculturalism? From Multiculturalism to Civil Intergration", Policy Futures in Education, Vol.12, No. 1 (January 2014): 1-15.

Prasisko, Yangki Gigih, "Gerakan Sosial Baru Indonesia:Reformasi 1998 dan Proses Demokratisasi Indonesia", Jurnal Pemikiran sosiolog, Vol. 3 No. 2 (August 2016): 9-16.

Qodir, Zuli. "Islamic Thought, Nationalism, and Multiculturalism”, Al-Albab, Vol. 3, No. 1 (June 2014): 2538.

Rosyad, Ali Miftakhu, "The Integration of Islamic Education and Multicultural Education in Indonesia. AlAfkar, vol 3, No. 1 (January 2020):164-181.

Rois, Achmad. "Pendidikan Islam Multikultural: Telaah Pemikiran Muhammad Amin Abdullah", Epistemé: Jurnal Pengembangan Ilmu Keislaman, Vol. 8, No. 2 (December 2013): 302-22.

Samson, Frank L. "An Association between Multiculturalism and Psychological Distress", PLoS ONE, Vol. 13, No. 12 (December 2018): 1-15.

Shihab, Alwi. Islam Inklusif: Menuju Sikap Terbuka dalam Beragama. Bandung: Mizan, 1999.

Slamet et. al. "The Implementation of Multicultural Values in The Educational Insitution", The Journal of Educational Development, Vol. 5, No. 1 (February 2017): 118-127.

Suparlan, Parsudi. "Kesetaraan Warga dan Hak Budaya Komuniti dalam Masyarakat Majemuk Indonesia", Antropologi Indonesia, Tahun XXV, No. 66 (Desember 2001).

Suyanto, Totok et. al. "Presepsi, Sikap, dan Pengetahuan Guru Sekolah Dasar di Kotamadya Surabaya Terhadap Pengajaran Multikultral, Lembaga Penelitian Universitas Negeri Surabaya, Not Published.

Tolchah, Moch and Mu'ammar, Muhammad Arfan. "Islamic Education In The Globalization Era; Challenges , Opportunities , And Contribution Of Islamic Education In Indonesia", Humanities \& Social Sciences Reviews, Vol. 7, No. 4 (October 2019): 1031-1037.

UNESCO.Learning to Live Together: Education Polices and Realitis in the Asia-Pacific. Paris: Place De Fontenoy, 2014.

Warsono et. al. "Model Pengembangan Pendidikan Multikultur Bagi Siswa Madrasah Ibtidaiyah dengan Pendekatan Multimedia Sebagai Upaya Peningkatan Wawasan Kebangsaan. Jurnal Studi Islam, Sains, dan Teknologi, (2006).

Wibisono, Susilo et al. "A Multidimensional Analysis of Religious Extremism", Frontiers in Psychology, Vol. 10 (November 2019): 1-12.

Zhang, Junhao. "Educational Diversity and Ethnic Cultural Heritage in the Process of Globalization", International Journal of Anthropology and Ethnology, Vol. 3, No. 7 (May 2019): 1-10. 